\title{
Health care workers depression and associated factors during COVID-19. Health facility-based study in Eastern Ethiopia
}

Tesfaye Assebe Yadeta ( $\square$ tesfaye.assb@gmail.com)

Haramaya University College of Health and Medical Sciences https://orcid.org/0000-0003-3015-8979

Yadeta Desie Baca

Haramaya University

Bikila Balis

Haramaya University College of Health and Medical Sciences

\section{Research}

Keywords: Health worker, depression, COVID_19, East, Ethiopia

Posted Date: December 29th, 2020

DOI: https://doi.org/10.21203/rs.3.rs-135135/v1

License: () (i) This work is licensed under a Creative Commons Attribution 4.0 International License. Read Full License 


\section{Abstract \\ Background}

Depression of health care workers was related to work absences, resignations, and poor work performance, affecting the quality of patient care and the health care system. It may be at higher risk during the Coronavirus disease (COVID-19) pandemic. There is limited evidence that assesses depression and its associated factors in the study area. Therefore this study aimed to assess depression and associated factors among health care workers (HCW) in eastern Ethiopia.

\section{Method:}

The cross-sectional study design was conducted from October 26th to November 10, 2020. To assess depression among health care workers. Patient Health Questionnaire (PHQ-19) questionnaire was used for the collection of depressive symptoms. The data were analyzed by using STATA version 14 software. Adjusted Odds Ratio (AOR) along with $95 \% \mathrm{Cl}$ was estimated to examine factors associated with depression symptoms using logistic regression analysis.

\section{Results}

Of the total 265 study participant, $176(66.4 \%)$ and $95 \% \mathrm{Cl}: 60.4 \%, 71.8 \%$ of them reported depressive symptom. Of 176 reported symptoms of depression $27.9 \%, 24.1 \%, 9.4 \%, 3.7 \%$, and $1.1 \%$ were had minimal, mild, moderate, moderate-severe, and severe depressive symptoms respectively. Being female [AOR: 3.40, (95\% Cl: $(1.79,6.45)$ ], participants who perceived susceptibility to COVID-19 [AOR: $2.30,(95 \% \mathrm{Cl}:(1.12,4.71)$ ], and perceived severity to COVID-19 [AOR: 3.06, (95\% Cl: $(1.35,6.91)]$ were higher risks of experiencing depression symptoms. Participants who had work experience $3-5$ years [AOR: 0.21 , (95\%Cl: (0.08, $0.56)$ ], and the participant who had $6-10$ years' work experience [AOR: $0.30,(95 \% \mathrm{Cl}:(0.11,0.84)$ ] were had less likely to experience depression symptoms when compared with a participant who had two and fewer years of work experience.

\section{Conclusions}

A high proportion of health care workers experienced depression symptoms. Health care workers' mental health needs to be protected during the COVID-19 pandemic. Female health care workers, junior health care workers, and HCWs perceived susceptibility, and perceived severity of COVID-19 need attention.

\section{Background}

Since the World Health Organization (WHO) declared coronavirus disease 2019 (COVID-19) a pandemic, it became a major challenging public health problem worldwide[1]. Globally, many countries have been affected by the pandemic, as of October 27, 2020; there were 43,873,412 recorded cases and 1,166,039 fatalities [1]. During the same period, 93,707 cases and 1,437 fatalities were recorded in Ethiopia[2]. Similarly, more than 10,000 health care workers (HCWs) in the 40 countries of Africa have been infected with COVID-19[3].

With the ever-growing number of confirmed and suspected cases, the workload of HCWs has been overwhelming [4]. The long and irregular hours of such continuous and heavy volumes of work have the potential to trigger depression among HCWs [5-8]. Safety measures like lockdown and physical distancing recommended by the world health organizations to limit the spread of pandemics among the public, but health care workers (HCWs) are left exposed[9]. Globally, the prevalence of depression among HCWs range from 18-72\% [10-16]. Also, they are burdened with emotionally challenging interactions with the sick and potentially dying persons, fearing for their and families' health, and subject to occupational overload due to staff shortages and insufficient personal protective equipment [17].

Many studies documented as HCWs face physical exhaustion, sleep disruption, fear, emotional disturbances, feeling vulnerable, loss of control, changes in working patterns/routine, feelings of personal danger, being isolated, lacking necessary supplies to conduct their work due to the pandemic [4, 18-20]. This may increase their risk of depression, suicide, and burnout. Depression symptoms were related to work absences resignations and poor work performance, affecting patient care and the healthcare system $[15,21]$.

The study suggests that HCWs with depression benefit from care involving medical and psychological interventions [22]. World Health Organization identified protecting the mental wellbeing of healthcare workers caring for people with COVID-19 has been identified as crucial for the long-term capacity of the HCWs [23]. However, most HCWs experiencing depression were not planning to seek help and $30 \%$ were not aware of workplace help programs. This may be due to a lack of information on the prevalence and associated factors of depression. There is a limited study in Ethiopia that assess depression and associated factors among health care workers. Therefore, this study aimed to assess depression status and associated factors among health care workers during COVID-19 pandemic in the Eastern part of Ethiopia.

\section{Methods And Materials}

\section{Study setting and period}

The study was conducted among health facilities found in the Eastern Hararghe Zone, Oromia regional states found in eastern part of Ethiopia. The East Hararge Zone is bordered on the southwest by Bale, on the west by West East Shewa Zone, on the north by Dire Dawa and on the north and east by the Somali 
Region. The Harari regional state is an enclave inside this zone. The Administrative center of this zone is Harar city. The East Hararghe zone contains four hospitals, and 67 health centers according to the East Hararghe health bureau report [24]. The study was conducted from October 25 to November $15,2020$.

\section{Study design and source population}

Health facilities based cross-sectional study design was used. All health care workers from randomly selected health facilities found in the Eastern Hararghe zone were the study population. Health care workers who unable to communicate due to illness were excluded.

\section{Sample size determination}

The sample size was calculated using the formula for estimation of a single population proportion $(n=[(Z a / 2) 2 * P(1-P)] / d 2)$ with the assumptions of $95 \%$ confidence level, marginal error (d) of 0.05 , and $50.4 \%$ the prevalence of depression among health care workers [25]. Thus, after applying the finite population correction formula and adding $10 \%$ of the non-response rate, the final sample size obtained was 297.

\section{Sampling procedure and sampling technique}

Two hospitals and eight health centers were selected by simple random sampling method (lottery method) from four hospitals and 39 health centers. The study participants from each selected health facilities were selected by simple random sampling technique by considering proportional to the institutions health professionals' size.

\section{Variables}

Dependent variable was depression.

Independent variables were socio-demographic characteristics such as age, marital status, and level of education, work experience, Perceived susceptibility, perceived severity, and perceived benefit.

\section{Data collection and questionnaire}

An interview questionnaire was developed to assess socio-demographic characteristics include; age sex, marital status, educational level, type of profession, types of health facility, and worker experiences. The 9-item Patient Health Questionnaire (PHQ-9) tool was used to assess depression symptoms. The questionnaire was validated in the Ethiopian context and it recommended for use [26].

The data was collected by ten nurses. Four MSC health professionals were assigned to supervise the data collection process. Both the data collectors and supervisors were taken 2-day intensive training before the actual work about the aim of the study, procedures, data collection techniques, the art of interviewing, ways of collecting the data, and clarification. The intensive supervision was done by the principal investigator, co-investigators and supervisors. Completeness, accuracy, and consistency of data were checked at the site of data collection throughout the data collection period. Finally, double data entry was done by two data clerks, and consistency of the entered data was cross-checked by comparing the two separately entered data.

\section{Measurements}

The PHQ-9 is the depression module, which scores each of the nine DSM-IV criteria as 0 to 3 for every nine symptoms of depression, "0" not at all, "1" several days " 2 " more than half the days " 3 " nearly every day. Scoring was done by counting the number of boxes checked in a column. Multiply that number by the value indicated above, then add the subtotal to produce a total score. PHQ-9 total score for the nine items ranges from 0 to 27 . Scores of zero, 1-4, 5-9, 10-14, 15-19, and 20-27 represent cut-points for no depression symptoms, minimal, mild, moderate, moderately severe, and severe depression, respectively [27]. For logistic regression analysis we have categorized those who had no symptom as have no depression and coded as " 0 " and the rest who had at least one symptom categorized as had depression symptoms and coded as" 1 "

The age of the mother was recorded based on maternal response later and was grouped as 19-24, 25-29, 30-34, 35-39, and $\geq 40$ with codes 1,2,3,4,and 5, respectively, for analysis. Work experience was grouped as $<2$ years, $3-5$ years, $6-10$ years, and $>10$ years with codes $1,2,3$, and 4 , respectively, for analysis. Data for perceived susceptible was collected by interview using a single question "How likely do you think it is that you will develop COVID-19 during your providing care?" liker scale of five were used and labeled as "Strong unlikely", "unlikely", "Neutral", "likely", and "Strongly likely" and coded with 1, 2, 3, 4, and 5 respectively. For logistic regression analysis, we categorize as strong unlikely, unlikely, and neutral as no perceived susceptible, no susceptible coded as " 1 " and susceptible coded as " 2 ". With a similar pattern. Data for perceived severity was collected by interview using question with a single question "Getting COVID-19 in the future worries me and It is important for me to prevent getting". Likert scale of five was used and labeled as "Strong unlikely", "unlikely", "Neutral", "likely", and "Strongly likely" and coded with 1, 2, 3, 4, and 5 respectively. For logistic regression analysis, we categorize as strong unlikely, unlikely, and neutral as no perceived susceptible, no susceptible coded as "1" and susceptible coded as "2".

\section{Interpretation}

PHQ-9 questionnaire is not a screening tool for depression but it is used to monitor the severity of depression and response to treatment. However, it can be used to make a tentative diagnosis of depression in at-risk populations (Table 1).

Table 1: Adapted interpretation of the PHQ-9 Scores for tentative diagnosis of depression in at-risk populations (Table 1). 


\begin{tabular}{|c|c|c|}
\hline Interpreting PHQ-9 Scores & & Action \\
\hline Minimal depression & $0-4$ & The score suggests the patient may not need depression treatment \\
\hline Mild depression & $5-9$ & \multirow{2}{*}{$\begin{array}{l}\text { Physician uses clinical judgment about treatment, based on patient's duration of symptoms and functional } \\
\text { impairment }\end{array}$} \\
\hline Moderate depression & $\begin{array}{l}10- \\
14\end{array}$ & \\
\hline $\begin{array}{l}\text { Moderately severe } \\
\text { depression }\end{array}$ & $\begin{array}{l}15- \\
19\end{array}$ & \multirow[t]{2}{*}{ Warrants treatment for depression, using antidepressant, psychotherapy and/or a combination of treatment } \\
\hline Severe depression & $\begin{array}{l}20- \\
27\end{array}$ & \\
\hline
\end{tabular}

\section{Statistical Analysis}

Double data entry was made using the Epidata 3.1 software. Then after validation was done the data exported to the STATA statistical package version 14 for further analysis. Descriptive statistics were used to summarize the variable. Continuous variables like age and work experience were first transformed into categorical variables before analyzed. Initially, the crude odds ratio (COR) along with a $95 \%$ confidence interval was estimated to assess the association between each independent variable and the outcome variable. Multicollinearity was tested using the Variance Inflation Factor (VIF) test and the tolerance test. No multicollinearity problem was found. The Hosmer-Lemeshow goodness-of-fit tests were used to test for model fitness [25]. The logistic regression model was used to assess the association between predictor variables and the outcome variable depression symptoms. Adjusted Odds Ratio (AOR) along with a 95\% confidence interval was estimated to assess the strength of the association. Statistical significance was declared at a $p$-value $\leq$ of 0.05

\section{Ethical consideration}

The study was approved by the Haramaya University, College of Health and Medical Sciences Institutional Health Research Ethics Review Committee (IHRERC). The permission and agreement consent was obtained from East Hararghe Zone, participating District health bureau, and health care facilities office prior to the study. The study participant was informed about the purpose of the study, their right to refuse, and written and signed voluntary consent was obtained prior to data collection. Based on the interpretation and recommendation HCWs who had depression symptoms were obtained management.

\section{Results}

\section{Socio-demographic characteristics of the respondents}

A total of 265 health care workers were participated in this study. The mean ( \pm SD) age of HCWs was 29.29 ( \pm 6.40$)$ years. The mean $( \pm$ SD) HCWs work experience was 6.25 ( \pm 4.98 ) years. Of these, 69(26.04\%) were working in outpatient department, $49(18.49 \%)$ were working in mother and neonatal health, the majorities 118 (44.53\%) were nurse in profession, and more than two-third 183(69.06\%) were married (Table 2). 
Table 2

Socio-demographic characteristics of respondents in in Eastern Hararghe zone, Oromia region, Eastern Ethiopia, 2020.

\begin{tabular}{|c|c|c|c|}
\hline Characteristics & Category & Frequency & percent \\
\hline \multirow[t]{5}{*}{ Age } & $19-24$ & 35 & 13.21 \\
\hline & $25-29$ & 135 & 50.94 \\
\hline & $30-34$ & 60 & 22.64 \\
\hline & $35-39$ & 18 & 6.79 \\
\hline & $\geq 40$ & 17 & 6.42 \\
\hline \multirow[t]{4}{*}{ Work experience } & $<2$ years & 55 & 20.75 \\
\hline & $3-5$ years & 81 & 30.57 \\
\hline & $6-10$ years & 90 & 33.96 \\
\hline & $>10$ years & 39 & 14.72 \\
\hline \multirow[t]{2}{*}{ Type of facility } & Health center & 167 & 63.02 \\
\hline & Hospital & 98 & 36.98 \\
\hline \multirow[t]{10}{*}{ Ward/area } & OPD & 69 & 26.04 \\
\hline & ART/TB & 15 & 5.66 \\
\hline & Gyen /Obstetric & 46 & 17.36 \\
\hline & $\mathrm{MCH}$ & 49 & 18.49 \\
\hline & Emergency/ICU/X & 24 & 9.06 \\
\hline & Surgical & 8 & 3.02 \\
\hline & Medical & 14 & 5.28 \\
\hline & Lab & 12 & 4.53 \\
\hline & Pharmacy & 16 & 6.04 \\
\hline & Pediatrics & 10 & 3.77 \\
\hline \multirow[t]{6}{*}{ Profession } & Nurse & 118 & 44.53 \\
\hline & Public health & 28 & 10.57 \\
\hline & Midwifery & 71 & 26.79 \\
\hline & Pharmacy & 17 & 6.42 \\
\hline & MLT & 13 & 4.90 \\
\hline & Medical Dr. & 18 & 6.79 \\
\hline \multirow[t]{4}{*}{ Level of education } & Diplo & 101 & 38.11 \\
\hline & Bsc & 144 & 54.34 \\
\hline & $\mathrm{MSc} / \mathrm{MPH}$ & 2 & 0.75 \\
\hline & Doctors & 18 & 6.79 \\
\hline \multirow[t]{2}{*}{ Sex } & Male & 149 & 56.23 \\
\hline & Female & 116 & 43.77 \\
\hline \multirow[t]{2}{*}{ Marital status } & Unmarried & 82 & 30.94 \\
\hline & Married & 183 & 69.06 \\
\hline
\end{tabular}

\section{COVID-19 related perception}

Participant response on perceived susceptibility, perceived severity, and perceived benefit indicated as $96(36.23 \%)$ participants were strongly perceived as they perceived susceptible in experienced COVID-19 during care provision, 121(45.66\%) respondents believe regular use of the mask is an effective way of avoiding COVID-19, 114 (54.34\%) of respondents were regularly used mask (Table 3 ). 
Table 3

Assessment of health care workers COVID-19 related perceived susceptibility and severity in Eastern Hararghe zone, Oromia region, Eastern Ethiopia, 2020.

\begin{tabular}{|c|c|c|c|c|c|c|c|c|c|c|}
\hline \multirow[t]{2}{*}{ Characteristics } & \multicolumn{2}{|c|}{$\begin{array}{l}\text { Strong } \\
\text { unlikely }\end{array}$} & \multicolumn{2}{|c|}{ unlikely } & \multicolumn{2}{|c|}{ Neutral } & \multicolumn{2}{|c|}{ likely } & \multicolumn{2}{|c|}{$\begin{array}{l}\text { Strong } \\
\text { likely }\end{array}$} \\
\hline & $\mathrm{n}$ & $\%$ & $\mathrm{n}$ & $\%$ & $\mathrm{n}$ & $\%$ & $\mathrm{n}$ & $\%$ & $\mathrm{n}$ & $\%$ \\
\hline $\begin{array}{l}\text { How likely do you think it is that you will develop COVID-19 during your } \\
\text { providing care?" }\end{array}$ & 25 & 9.43 & 38 & 14.34 & 13 & 4.91 & 93 & 35.09 & 96 & 36.23 \\
\hline $\begin{array}{l}\text { Getting COVID-19 in the future worries me" and "It is important for me to } \\
\text { prevent getting }\end{array}$ & 25 & 9.43 & 18 & 6.79 & 14 & 5.28 & 114 & 43.02 & 94 & 35.47 \\
\hline Regular use of mask is an effective way of avoiding COVID-19 & 13 & 4.91 & 16 & 6.04 & 12 & 4.53 & 114 & 54.34 & 80 & 30.19 \\
\hline Regular use of glove is an effective way of avoiding COVID-19 & 21 & 7.92 & 27 & 10.19 & 23 & 8.68 & 121 & 45.66 & 73 & 27.55 \\
\hline Regular use of goggle is an effective way of avoiding COVID-19 & 34 & 12.88 & 27 & 10.23 & 15 & 5.68 & 120 & 45.45 & 68 & 25.76 \\
\hline
\end{tabular}

\section{Categorized COVID-19 related perceived susceptibility and severity}

After categorizing, 202(76.23\%) and 222(83.77\%) respondents were perceived as susceptible and perceived severe to COVID-19 respectively (Table 4).

Table 4

COVID-19 related Susceptibility and Severity in Eastern

Hararghe zone, Oromia region, Eastern Ethiopia, 2020.

\begin{tabular}{|llll|}
\hline Characteristics & Category & Frequency & Percent \\
\hline Perceived susceptibility & No & 63 & 23.77 \\
\cline { 2 - 4 } & Yes & 202 & 76.23 \\
Perceived severity & No & 43 & 16.23 \\
\cline { 2 - 4 } & Yes & 222 & 83.77 \\
\hline
\end{tabular}

\section{Depression status of participants}

More than half, $148(55.85 \%)$ of respondents not at all had interest or pleasure in doing things over the past two weeks. Two third 174 (65.66\%) of the respondents not at all feeling down, depressed, or hopeless, feeling tired 171 (64.53\%) and trouble concentrating on things, such as reading the newspaper or watching television 173 (65.28\%) over the past two weeks(Table 5).

Table 5

Depression status of health care workers in Eastern Hararghe zone, Oromia region, Eastern Ethiopia, 2020.

\begin{tabular}{|c|c|c|c|c|c|c|c|c|}
\hline \multirow[t]{2}{*}{ Characteristics } & \multicolumn{2}{|c|}{ Not at all } & \multicolumn{2}{|c|}{$\begin{array}{l}\text { Several } \\
\text { days }\end{array}$} & \multicolumn{2}{|c|}{$\begin{array}{l}\text { More than } \\
\text { half the } \\
\text { days }\end{array}$} & \multicolumn{2}{|c|}{$\begin{array}{l}\text { Nearly } \\
\text { every day }\end{array}$} \\
\hline & $\mathbf{n}$ & $\%$ & $\mathbf{n}$ & $\%$ & $\mathbf{n}$ & $\%$ & $\mathbf{n}$ & $\%$ \\
\hline Little interest or pleasure in doing things & 148 & 55.85 & 54 & 20.38 & 34 & 12.83 & 29 & 10.94 \\
\hline Feeling down, depressed, or hopeless & 174 & 65.66 & 42 & 15.85 & 37 & 13.96 & 12 & 4.53 \\
\hline Trouble falling or staying asleep, or sleeping too much & 196 & 73.96 & 27 & 10.19 & 31 & 11.70 & 11 & 4.15 \\
\hline Feeling tired or having little energy & 171 & 64.53 & 44 & 16.60 & 41 & 15.47 & 9 & 3.40 \\
\hline Poor appetite or overeating & 208 & 78.49 & 23 & 8.68 & 23 & 8.68 & 11 & 4.15 \\
\hline Feeling bad about yourself or that you are a failure or & 214 & 80.75 & 22 & 8.30 & 20 & 7.55 & 9 & 3.40 \\
\hline Trouble concentrating on things, such as reading the newspaper or watching television & 173 & 65.28 & 48 & 18.11 & 22 & 8.30 & 22 & 8.30 \\
\hline $\begin{array}{l}\text { Moving or speaking so slowly that other people could have noticed. Or the opposite being so } \\
\text { fidgety or restless that you have been moving around a lot more than usual }\end{array}$ & 193 & 72.83 & 38 & 14.34 & 24 & 9.06 & 10 & 3.77 \\
\hline Thoughts that you would be better off dead, or of hurting yourself & 234 & 88.30 & 16 & 6.06 & 10 & 3.77 & 5 & 1.89 \\
\hline
\end{tabular}

\section{Level of depression of participants}

Concerning the level of depression of respondents, $176(66.4 \%)$ and $95 \% \mathrm{Cl}: 60.4 \%, 71.8 \%)$ of them reported at least one depressive symptom. Of respondents who had symptoms of depression, $74(27.92 \%)$ had minimal and $64(24.15 \%)$ were had mild symptoms of depression (Fig. 1).

\section{Factors associated with depression}


In multivariable regression analysis the Odds of being female [AOR: $3.40,(95 \% \mathrm{Cl}$ : $(1.79,6.45)$ ], participants who perceived susceptibility [AOR: 2.30 , (95\% Cl: $(1.12,4.71)]$, and perceived severity [AOR: $3.06,(95 \% \mathrm{Cl}$ : $(1.35,6.91)]$ were higher risks of experiencing depression symptoms. Participants who had work experience $3-5$ years [AOR: $0.21,(95 \% \mathrm{Cl}:(0.08,0.56)$, and the participant who had $6-10$ years' work experience $[\mathrm{AOR}: 0.30,(95 \% \mathrm{Cl}:(0.11,0.84)]$ were less likely to experience depression symptoms when compared with a participant who had two and fewer years of work experience (Table 6).

Table 6

Factors associated with the depression of health care workers in Eastern Hararghe zone, Oromia region, Eastern Ethiopia, 2020.

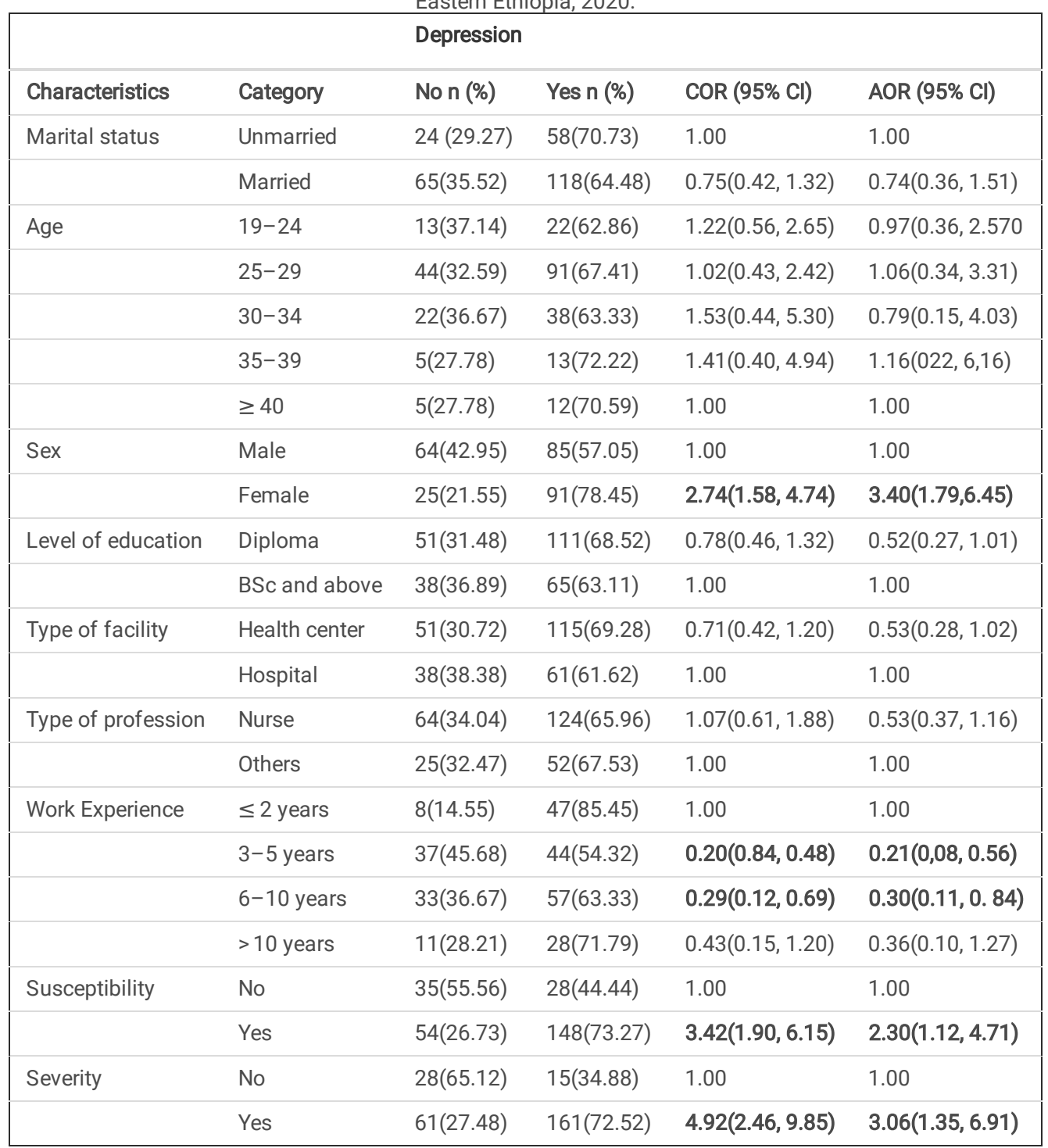

\section{Multicollinearity test}

Multicollinearity was tested using the Variance Inflation Factor (VIF) and tolerance test. Variance Inflation Factor for all variables was less than five. Variance Inflation Factor below 5 is believed non-significant multicollinearity and therefore there is no need for correction [28] (Table 7). 
Table 7

Multicollinearity test output among predictor variables, Harar, Eastern Ethiopia,

2016

\begin{tabular}{|lll|}
\hline Variables & Variance inflation test (VIF) & Tolerance test (1/VIF) \\
\hline Experience & 1.37 & 0.729844 \\
\hline Age & 1.37 & 0.730546 \\
\hline Perceived severity & 1.25 & 0.798794 \\
\hline Perceived susceptibility & 1.21 & 0.827699 \\
\hline Martials status & 1.19 & 0.840225 \\
\hline Educational level & 1.19 & 0.842732 \\
\hline Profession & 1.14 & 0.873767 \\
\hline Facilities & 1.12 & 0.891002 \\
\hline sex & 1.11 & 0.903292 \\
\hline Mean VIF & 1.22 & \\
\hline
\end{tabular}

\section{Discussion}

In this study, overall, 276 (66.42\%) of the study participants have had at least one self-reported depression symptoms. Factors significantly associated with depression symptoms were being a female, work experiences, perceived susceptibility, and perceived severity.

The depression symptoms reported in this study was consistent with those reported in studies conducted elsewhere [29-33]. This may be due to fears and concerns for self, family members, problems with children and spouses, and difficulties entailed in working at home are some of the stressors during the Covid-19 pandemic [34]. This may also due to, Ethiopia is one of low income countries which left HCWs with high fear of COVID-19 due to lack of personal protective equipment(PPE) and shortage of human power to handle ever increasing the case [14, 35], and low preparedness to compact the pandemic [35-37]. As some bodies experience stress, adrenal glands make and release cortisol hormone into the bloodstream. Prolonged elevated cortisol level leads to the manifestation of depression [38-40] and minimize the body immunity [41]. Health care providers at higher risk of experiencing severe disease and even may fatal. ICN confirms 1,500 nurses have died from COVID-19 in 44 countries and estimates that healthcare worker COVID-19 fatalities worldwide could be more than 20,000 as of October 28, 2020 [42]. Without addressing mental health services, we risk not having a workforce left to care for us.

The study showed depression symptoms were higher among female health care workers. This is supported by studies conducted in China [19, 43], Gulian [44], Egypt[45] and Ethiopia[46]. Women are among the highly vulnerable population groups during a pandemic due to disrupting the food system and other economic activities. A study in India showed COVID-19 case fatality rate among men were $2.9 \%$ and $3.3 \%$ among women [47]. Study showed that, there was gender difference in stress and coping styles, numerous studies have determined that women find themselves in stressful circumstances more often than men, and their coping style is more emotion-focused than that of men [48]. Social roles also seem relevant in the stressful life experiences of women, especially in low-income countries. There can be sex differences in the use of coping strategies which is important for the mitigation of depressive symptoms [49]. The study shows that certain psychological and social determinants were associated with increased depressive symptoms, women are disadvantageous in low-income country, COVID-19 enhances the vulnerability to the mental health challenge [50]. Measures must be put into place to ensure the protection of women on the frontlines while reducing COVID-19 deaths and adverse health effects among displaced populations.

This study also showed work experience was significantly associated with had symptoms of depression. Health workers who had less work experience had developed more depressive symptoms. This found to be in line with a finding study done in Nepal [51]. The study showed a lack of communication skills with patient, among health professionals and colleague, medical knowledge, and skills associated with depression symptoms [52], less experience may weaken self-regulation ability and copying mechanism for stressor [22]. Training on knowledge and skill and schedule for activities mixing senior professionals who had skill and experience with junior health workers may benefit.

Perceived susceptibility (perception of the risk of acquiring COVID-19) was associated with participants who had symptoms of depression. This is consistent with the study finding in China $[53,54]$. Also, participants who perceived the severity of COVID-19 were six times more likely to develop depression compared with their counterparts. This is in line with a study done in China[19]. Perceived susceptibility may be related to shortages of personal protective equipment (PPE) or other essential equipment, low community role in practice to protect themselves and the play their role in mitigating the transmission including to the health care worker [55]. Contradicting of belief in susceptibility and severity, with the low accessibility of protective measure, less concern of the community and the health manager may put health care provider at risk of experiencing depressive symptoms. Health care may also face moral dilemmas in decisionmaking around the provision of care with limited resources [6].

Depression symptoms were related to work absences and reduced work performance. The study investigated that workers with depression may benefit from care involving medical and psychological interventions [22]. World Health Organization identified protecting the mental wellbeing of healthcare workers caring for people with COVID-19 has been recognized as crucial for the long-term capacity of the health workforce [23]. However, most health care workers experiencing depression were not planning to seek help and not aware of workplace help plan [22]. Prioritizing the wellbeing of health care workers must be at the forefront of the action plan to tackle the coming wave of this pandemic. We suggested that comprehensive psychological assistance should be provided to support the mental well-being of healthcare workers. 
Strengths, limitations, and future directions

The study conducted in multiple health care facilities including Hospitals and Health Centers found in town and rural areas. However, the cross-sectional study is important to be aware of the predictive, there is generally no evidence of a temporal relationship between exposure and outcome because the exposure and outcome are simultaneously assessed. The study includes only depressive symptoms, other mental health problems were not included. This study also not include staff who had contact with COVID-19 patients. We suggest a study that includes health professionals who had contact with COVID-19 patients, assessment of other mental health problems, longitudinal studies that assess the prolonged implication on HCWs need further investigation.

\section{Conclusion}

A high proportion of health care providers experienced depression symptoms. The mental health of healthcare workers should be protected during the COVID19 pandemic. Female health workers, junior health workers, have less work experience and perceived susceptibility, and perceived severity of COVID-19 need attention.

\section{Declarations}

\section{Acknowledgements}

The authors would like to thank Oromia Regional state Health Bureau for financial support, the study participants, for their generosity spent many hours responding to questionnaires. We wish to acknowledge the sterling contributions of our field workers, administrators, data personnel and other staff who contributed to the data collection.

Authors' contributions

TA.Y, YB, and BB conceived and designed the paper, involved in data collection, performed the statistical analysis, interpret the results, wrote and reviewed the manuscript. All authors read and approved the final version of manuscript before submission.

Funding

This study was financially supported by Oromia Regional state health bureau, Ethiopia.

Availability of data and materials

The datasets used and/or analyzed during the current study are available from the corresponding author on reasonable request.

\section{Ethics approval and consent to participate}

The written consent was obtained from each respondent. Privacy and confidentiality were resolutely kept in all data collection procedures. The study material was reviewed and approved by the Institutional Health Research Ethics Review Committee of the College of Health and Medical Sciences at Haramaya

University. Permission was obtained from each of the health facilities involved in the study.

\section{Consent for publication}

Not applicable

\section{Competing interests}

The authors declare that they have no competing interests.

\section{References}

1. WHO: Coronavirus disease (COVID-19) pandemic. Avaliable at https://www.worldometers.info/coronavirus/, accessed date October 27,2020. 2020.

2. FMOH: Coronavirus update , Ethiopia gov't covid-19 control center. Avaliable at https://www.google.com/aclk? sa=L\&ai=DChcSEwjymdTJ39TsAhWDse0KHRmIAnOYABAAGgJkZw\&sig=AOD64_170o6wqY2KWtnMgjJsH3mh9HGCew\&q\&adurl\&ved=2ahUKEwiSzMvJ accessed date October 27,2020. . 2020.

3. WHO: Over 10000 health workers in Africa infected with COVID-19. Avaliable at https://www.afro.who.int/news/over-10-000-health-workers-africainfected-covid-19, accessed date October 27,2020. 2020.

4. Zhan YX, Zhao SY, Yuan J, Liu H, Liu YF, Gui LL, Zheng H, Zhou YM, Qiu LH, Chen JH et al: Prevalence and Influencing Factors on Fatigue of First-line Nurses Combating with COVID-19 in China: A Descriptive Cross-Sectional Study. Current medical science 2020, 40(4):625-635.

5. Cai Z, Cui Q, Liu Z, Li J, Gong X, Liu J, Wan Z, Yuan X, Li X, Chen C et al: Nurses endured high risks of psychological problems under the epidemic of COVID-19 in a longitudinal study in Wuhan China. Journal of psychiatric research 2020, 131:132-137.

6. da Silva FCT, Neto MLR: Psychiatric symptomatology associated with depression, anxiety, distress, and insomnia in health professionals working in patients affected by COVID-19: A systematic review with meta-analysis. Progress in Neuro-Psychopharmacology and Biological Psychiatry $2020: 110057$.

7. Khanal P, Devkota N, Dahal M, Paudel K, Joshi D: Mental health impacts among health workers during COVID-19 in a low resource setting: a crosssectional survey from Nepal. Global Health 2020, 16(1):89.

Page $9 / 12$ 
8. Li Q, Chen J, Xu G, Zhao J, Yu X, Wang S, Liu L, Liu F: The Psychological Health Status of Healthcare Workers During the CoVID-19 Outbreak: A CrossSectional Survey Study in Guangdong, China. Front Public Health 2020, 8:562885.

9. Wilder-Smith A, Freedman DO: Isolation, quarantine, social distancing and community containment: pivotal role for old-style public health measures in the novel coronavirus (2019-nCoV) outbreak. Journal of travel medicine 2020, 27(2):taaa020.

10. Blake H, Bermingham F, Johnson G, Tabner A: Mitigating the Psychological Impact of COVID-19 on Healthcare Workers: A Digital Learning Package. Int J Environ Res Public Health 2020, 17(9).

11. Liang Y, Wu K, Zhou Y, Huang X, Zhou Y, Liu Z: Mental health in frontline medical workers during the 2019 novel coronavirus disease epidemic in China: a comparison with the general population. International Journal of Environmental Research and Public Health 2020, 17(18).

12. Alshekaili M, Hassan W, Al Said N, Al Sulaimani F, Jayapal SK, Al-Mawali A, Chan MF, Mahadevan S, Al-Adawi S: Factors associated with mental health outcomes across healthcare settings in Oman during COVID-19: frontline versus non-frontline healthcare workers. BMJ open 2020, 10(10):e042030.

13. Amin F, Sharif S, Saeed R, Durrani N, Jilani D: COVID-19 pandemic-knowledge, perception, anxiety and depression among frontline doctors of Pakistan. BMC Psychiatry 2020, 20(1):459.

14. Chen J, Liu X, Wang D, Jin Y, He M, Ma Y, Zhao X, Song S, Zhang L, Xiang X et al: Risk factors for depression and anxiety in healthcare workers deployed during the COVID-19 outbreak in China. Social psychiatry and psychiatric epidemiology 2020:1-9.

15. Gill S, Hao D, Hirte H, Campbell A, Colwell B: Impact of COVID-19 on Canadian medical oncologists and cancer care: Canadian Association of Medical Oncologists survey report. Current oncology (Toronto, Ont) 2020, 27(2):71-74.

16. Sandesh R, Shahid W, Dev K, Mandhan N, Shankar P, Shaikh A, Rizwan A: Impact of COVID-19 on the Mental Health of Healthcare Professionals in Pakistan. Cureus 2020, 12(7):e8974.

17. Huang JZ, Han M, Luo T, Ren A, Zhou X: Mental health survey of 230 medical staff in a tertiary infectious disease hospital for CoVID-19. Zhonghua lao dong wei sheng zhi ye bing za zhi= Zhonghua laodong weisheng zhiyebing zazhi=Chinese journal of industrial hygiene and occupational diseases 2020, 38:E001-E001.

18. Dong Z-Q, Ma J, Hao Y-N, Shen X-L, Liu F, Gao Y, Zhang L: The social psychological impact of the CoVID-19 pandemic on medical staff in China: A crosssectional study. European Psychiatry 2020, 63(1).

19. Lai J, Ma S, Wang Y, Cai Z, Hu J, Wei N, Wu J, Du H, Chen T, Li R: Factors associated with mental health outcomes among health care workers exposed to coronavirus disease 2019. JAMA network open 2020, 3(3):e203976-e203976.

20. An Y, Yang Y, Wang A, Li Y, Zhang Q, Cheung T, Ungvari GS, Qin MZ, An FR, Xiang YT: Prevalence of depression and its impact on quality of life among frontline nurses in emergency departments during the COVID-19 outbreak. J Affect Disord 2020, 276:312-315.

21. Dobson H, Malpas CB, Burrell AJ, Gurvich C, Chen L, Kulkarni J, Winton-Brown T: Bumout and psychological distress amongst Australian healthcare workers during the COVID-19 pandemic. Australasian psychiatry : bulletin of Royal Australian and New Zealand College of Psychiatrists 2020:1039856220965045.

22. Lerner D, Adler DA, Rogers WH, Lapitsky L, McLaughlin T, Reed J: Work performance of employees with depression: the impact of work stressors American Journal of Health Promotion 2010, 24(3):205-213.

23. (WHO). WHO: Mental Health and Psychosocial Considerations during the COVID-19 Outbreak. Available online: https://www.who.int/docs/defaultsource/coronaviruse/mental-health-considerations.pdf (accessed on 17 April 2020). 2020.

24. EHHB: East Hararghe Health Bureau report. 2012.

25. Lai J, Ma S, Wang Y, Cai Z, Hu J, Wei N, Wu J, Du H, Chen T, Li R et al: Factors Associated With Mental Health Outcomes Among Health Care Workers Exposed to Coronavirus Disease 2019. JAMA network open 2020, 3(3):e203976.

26. Degefa M, Dubale B, Bayouh F, Ayele B, Zewde Y: Validation of the PHQ-9 depression scale in Ethiopian cancer patients attending the oncology clinic at Tikur Anbessa specialized hospital. BMC psychiatry 2020, 20(1):1-7

27. Beck AT, Steer RA, \&William RB, Ranieri F: Comparison of Beck Depression Inventories-IA and-II in Psychiatric Outpatients Aaron T. Beck,Robert A. Steer,Roberta Ball \&William F. Ranieri Pages 588-597 | Published online: 10 Jun 2010. journal of persenality assessment 1996, 67(3).

28. Ringle CM, Wende S, Becker J-M: SmartPLS 3. Boenningstedt: SmartPLS GmbH 2015.

29. Wańkowicz P, Szylińska A, Rotter I: Assessment of Mental Health Factors among Health Professionals Depending on Their Contact with CoVID-19 Patients. Int J Environ Res Public Health 2020, 17(16).

30. Wańkowicz P, Szylińska A, Rotter I: Assessment of mental health factors among health professionals depending on their contact with COVID-19 patients. International Journal of Environmental Research and Public Health 2020, 17(16):5849.

31. Que J, Le Shi JD, Liu J, Zhang L, Wu S, Gong Y, Huang W, Yuan K, Yan W, Sun Y: Psychological impact of the COVID-19 pandemic on healthcare workers: a cross-sectional study in China. General psychiatry 2020, 33(3).

32. Sandesh R, Shahid W, Dev K, Mandhan N, Shankar P, Shaikh A, Rizwan A: Impact of COVID-19 on the mental health of healthcare professionals in Pakistan. Cureus 2020, 12(7).

33. Senbeta B, Geleta TA, Awol M: COVID-19 pandemic and self-reported symptoms of depression, anxiety, and stress among health care workers in Ethiopia. 2020.

34. Levkovich I, Shinan-Altman S: Impact of the COVID-19 pandemic on stress and emotional reactions in Israel: A mixed-methods study. 2020.

35. FMOH: National Comprehensive Covid19 Management Handbook. Avaliable at http://www.moh.gov.et/ejcc/en/node/196, accessed date October 27,2020. 2020 
36. Mulu GB, Kebede WM, Worku SA, Mittiku YM, Ayelign B: Preparedness and Responses of Healthcare Providers to Combat the Spread of CoVID-19 Among North Shewa Zone Hospitals, Amhara, Ethiopia, 2020. Infection and Drug Resistance 2020, 13:3171.

37. WHO: Technical guidance on infection prevention and control during the coronavirus (COVID-19) outbreak for the Western Pacific Region. Avaliable at https://www.who.int/westernpacific/emergencies/covid-19/technical-guidance/infection-prevention-control, accessed date October 27,2020. 2020.

38. Dinan TG: Glucocorticoids and the genesis of depressive illness a psychobiological model. The British Journal of Psychiatry 1994, 164(3):365-371.

39. Cowen P: Cortisol, serotonin and depression: all stressed out? The British Journal of Psychiatry 2002, 180(2):99-100.

40. Hannibal KE, Bishop MD: Chronic stress, cortisol dysfunction, and pain: a psychoneuroendocrine rationale for stress management in pain rehabilitation. Physical therapy 2014, 94(12):1816-1825.

41. Glacer R, Kiecolt-Glacer JK, Stout JC, Tarr KL, Speicher CE, Holliday JE: Stress-related impairments in cellular immunity. Psychiatry research 1985, 16(3):233-239.

42. International Council of Nurses (ICN): Press Release; Geneva, Switzerland, 28 October 20202020.

43. Zhu Z, Xu S, Wang H, Liu Z, Wu J, Li G, Miao J, Zhang C, Yang Y, Sun W: COVID-19 in Wuhan: Immediate Psychological Impact on 5062 Health Workers. MedRxiv 2020.

44. Pouralizadeh M, Bostani Z, Maroufizadeh S, Ghanbari A, Khoshbakht M, Alavi SA, Ashrafi S: Anxiety and depression and the related factors in nurses of Guilan University of Medical Sciences hospitals during COVID-19: A web-based cross-sectional study. International Journal of Africa Nursing Sciences 2020, 13:100233.

45. Elkholy H, Tawfik F, Ibrahim I, Salah El-din W, Sabry M, Mohammed S, Hamza M, Alaa M, Fawzy AZ, Ashmawy R: Mental health of frontline healthcare workers exposed to COVID-19 in Egypt: A call for action. International Journal of Social Psychiatry 2020:0020764020960192.

46. Kemal J, Berhanu S, Tinsae GA, Awol Mukemil: COVID-19 pandemic and self-reported symptoms of depression, anxiety, and stress among health care workers in Ethiopia. 2020.

47. Joe W, Kumar A, Rajpal S, Mishra U, Subramanian S: Equal risk, unequal burden? Gender differentials in COVID-19 mortality in India. Journal of Global Health Science 2020, 2(1).

48. Sibley CG, Overall NC: Modeling the hierarchical structure of attachment representations: A test of domain differentiation. Personality and Individual Differences 2008, 44(1):238-249.

49. Kelly MM, Tyrka AR, Price LH, Carpenter LL: Sex differences in the use of coping strategies: predictors of anxiety and depressive symptoms. Depression and anxiety 2008, 25(10):839-846.

50. Skapinakis P, Bellos S, Oikonomou A, Dimitriadis G, Gkikas P, Perdikari E, Mavreas V: Depression and its relationship with coping strategies and illness perceptions during the COVID-19 lockdown in Greece: a cross-sectional survey of the population. Depression research and treatment $2020,2020$.

51. Khanal P, Devkota N, Dahal M, Paudel K, Joshi D: Mental health impacts among health workers during CoVID-19 in a low resource setting: a crosssectional survey from Nepal. Globalization and Health 2020, 16(1):1-12.

52. Sen S, Kranzler HR, Krystal JH, Speller H, Chan G, Gelernter J, Guille C: A prospective cohort study investigating factors associated with depression during medical internship. Archives of general psychiatry 2010, 67(6):557-565.

53. Lam SC, Arora T, Grey I, Suen LKP, Huang EY-z, Li D, Lam KBH: Perceived Risk and Protection From Infection and Depressive Symptoms Among Healthcare Workers in Mainland China and Hong Kong During COVID-19. Frontiers in psychiatry 2020, 11:686.

54. Ying Y, Ruan L, Kong F, Zhu B, Ji Y, Lou Z: Mental health status among family members of health care workers in Ningbo, China, during the coronavirus disease 2019 (COVID-19) outbreak: a cross-sectional study. BMC Psychiatry 2020, 20(1):379.

55. Kebede Y, Yitayih Y, Birhanu Z, Mekonen S, Ambelu A: Knowledge, perceptions and preventive practices towards COVID-19 early in the outbreak among Jimma university medical center visitors, Southwest Ethiopia. PloS one 2020, 15(5):e0233744.

\section{Figures}




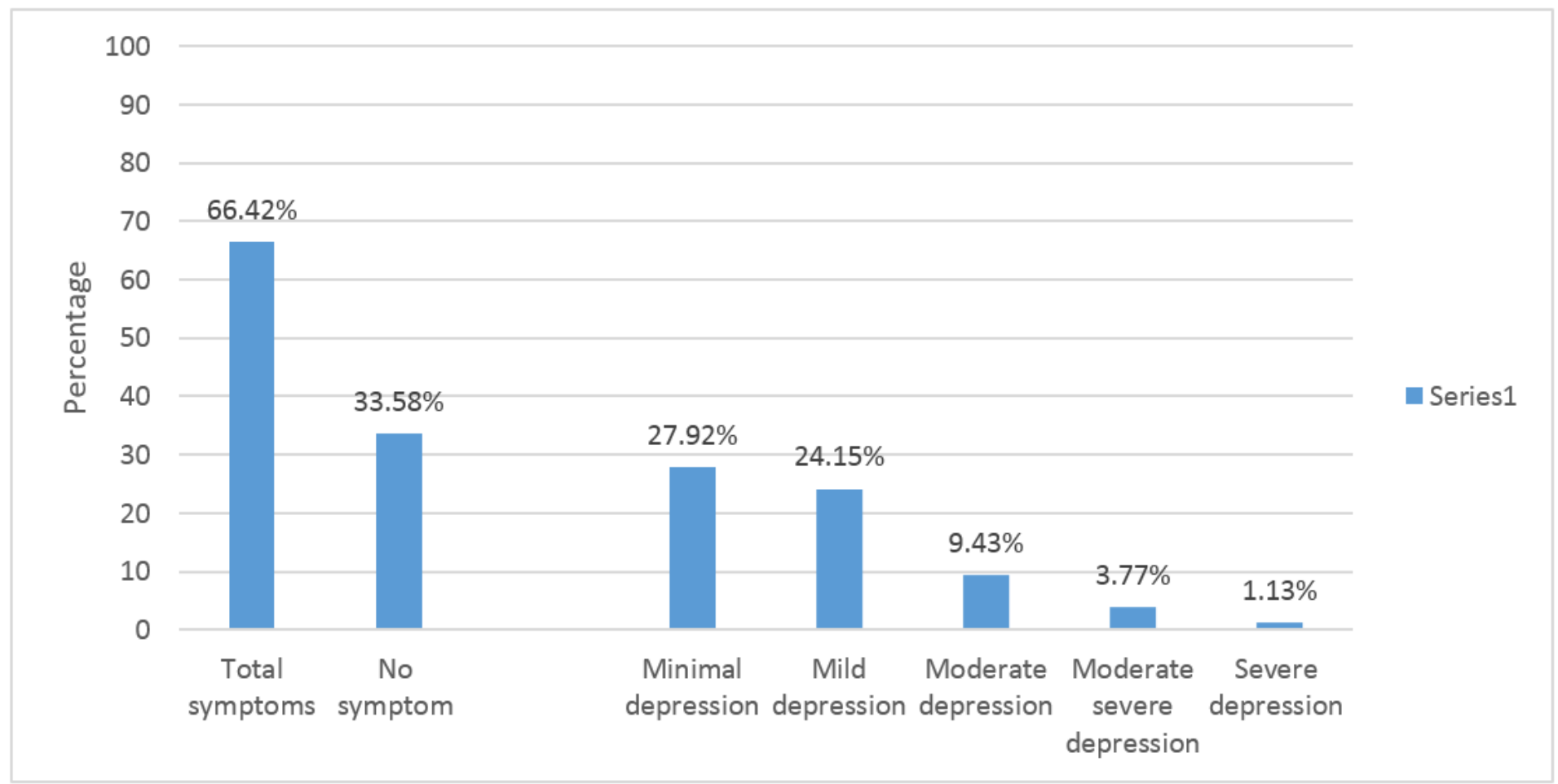

\section{Figure 1}

Level of depression among health care workers in Eastern Hararghe zone, Oromia region, Eastern Ethiopia, 2020 